\title{
Differences in Ponderosa Pine Isocupressic Acid Concentra- tions Across Space and Time
}

\section{By Daniel Cook, Dale R. Gardner, James A. Pfister, Kip E. Panter, Bryan L. Stegelmeier, Stephen T. Lee, Kevin D. Welch, Benedict T. Green, and T. Zane Davis}

\section{Historical Perspective}

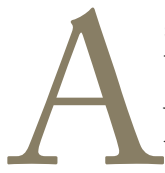

s early as 1927, ranchers in the northwestern United States and British Columbia, Canada, widely believed that consumption of pine needles by cattle predisposed animals to abortion and other reproductive problems. ${ }^{1}$ The abortive effects of pine needles were demonstrated by MacDonald, ${ }^{2}$ who showed that cattle would eat the needles of ponderosa pine (Pinus ponderosa) even though other feed was available, and that 2.3-2.9 kg/day of fresh buds and needles produced abortions in cattle. Since then, pine needle-induced abortion has been demonstrated in numerous other feeding trials $s^{3,4}$ (Fig. 1). This induced abortion is species-specific because it occurs only in cattle and bison; 4,5 attempts to reproduce the abortions in other species such as goats, sheep, and elk have failed. $^{4-6}$

Ponderosa pines are large coniferous trees characterized by yellowish-green needles that are $18-28 \mathrm{~cm}$ in length, with 2-3 needles per fascicle. ${ }^{7}$ Ponderosa pine is distributed throughout the western half of North America, where it is the most widely adapted and ubiquitous conifer. ${ }^{7}$ The species, $P$. ponderosa, is subdivided into three varieties: 1 ) var. ponderosa extends along the Pacific Coast from southern California northward to British Columbia and eastward to the continental divide in west-central Montana; 2) var. scopulorum extends eastward across Montana and southward throughout the Rocky Mountains, Great Basin, and Plains states, including South Dakota, Wyoming, Colorado, Utah, New Mexico, and the Kaibab Plateau in Arizona; and 3) var. arizonica is found in southern Arizona and northern Mexico. ${ }^{7}$ It is notable that ponderosa pine is not found in a large area that includes southwestern Montana, western Wyoming, southern Idaho, and parts of the Great Basin. The distribution of rainfall during the summer months might prevent seedling establishment in these areas. ${ }^{8}$
In the early 1960s, researchers tried to identify the abortifacient (or abortion-causing) compound in ponderosa pine, but most of these efforts met with limited success due to the lack of a small animal model. Using cattle, James and coworkers ${ }^{9}$ demonstrated that the abortion-causing compound(s) could be extracted effectively from needles using methylene chloride. Using bioassay-guided fractionation, wherein different extracted fractions were given to pregnant cattle, Gardner et al. ${ }^{10}$ identified isocupressic acid (ICA), a diterpene acid, as the abortion-causing compound. A number of ICA derivatives and/or metabolites also are abortifacient. ${ }^{11-13}$ The chemical composition of pine needles is quite complex, and ICA is only one of several diterpene acids found in ponderosa pine.

Further research has demonstrated that other gymnosperms contain ICA. ${ }^{14}$ Interestingly, the incidence of reported abortions in suspected abortion-causing plants, such as Monterey cypress and lodgepole pine, increases with increasing concentrations of ICA and/or its metabolic derivatives in those plants. Furthermore, the incidence, progression, and subsequent pathological conditions related to Monterey cypress-induced abortions are similar to that of ponderosa pine. ${ }^{15}$ Lodgepole pine and common juniper are also abortifacient in cattle. ${ }^{13}$

Currently, the mechanism of how ICA causes abortion in cattle fed pine needles is not known. Ford et al. ${ }^{16}$ demonstrated that the blood flow to the placental/fetal unit is decreased (vasoconstriction) in cattle fed pine needles. The subsequent stress to the fetus likely initiates parturition. However, ICA has not been shown to have direct vasoconstrictive properties. ${ }^{17} \mathrm{ICA}$ is metabolized readily ${ }^{12}$ and it might be that one of its metabolites is the compound responsible for reducing blood flow to the fetus. Further research is needed to identify the mechanism of toxicity, 


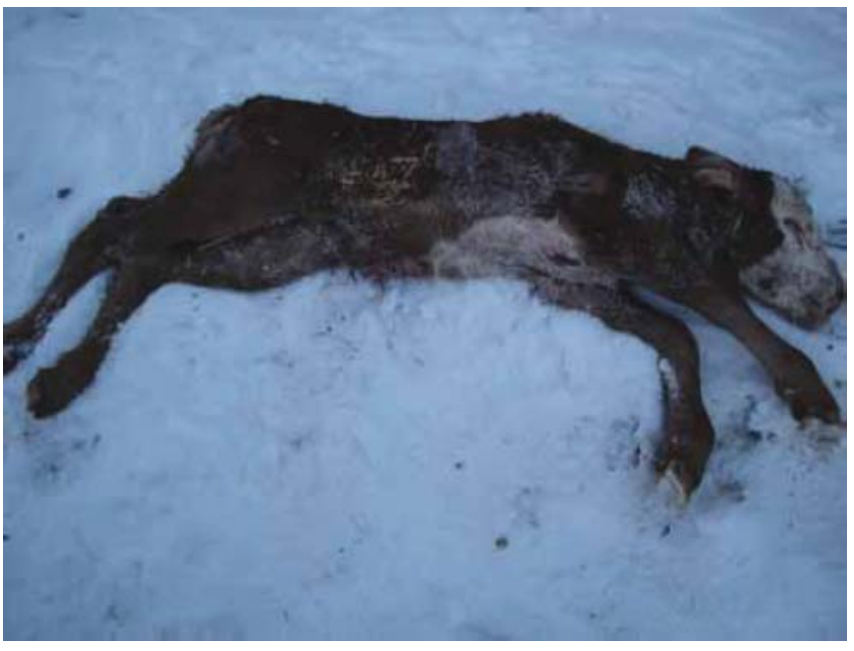

Figure 1. Calf aborted in late gestation from a cow fed ponderosa pine needles from South Dakota. Photo courtesy of J. Pfister.

the abortifacient ICA metabolite, the biological target, and potential methods to reduce or counteract these toxic effects.

\section{Management Recommendations}

Results from pen and field studies have shown that cattle will eat $20-40 \%$ of their diet as pine needles. ${ }^{2,18,19}$ Cattle eat fresh needles from the trees as well as dry needles from the ground litter (Fig. 2). Grazing cattle stressed by greater snow depth and lower minimum daily temperatures eat more pine needles, ${ }^{18,20}$ and during these conditions, thin cattle in low body condition will eat more pine needles than fat cattle in high body condition. ${ }^{20}$ Therefore, we recommend that pregnant cows be maintained in at least moderate to good body condition when grazing on pine needle-infested rangelands to reduce consumption and risk of abortions.

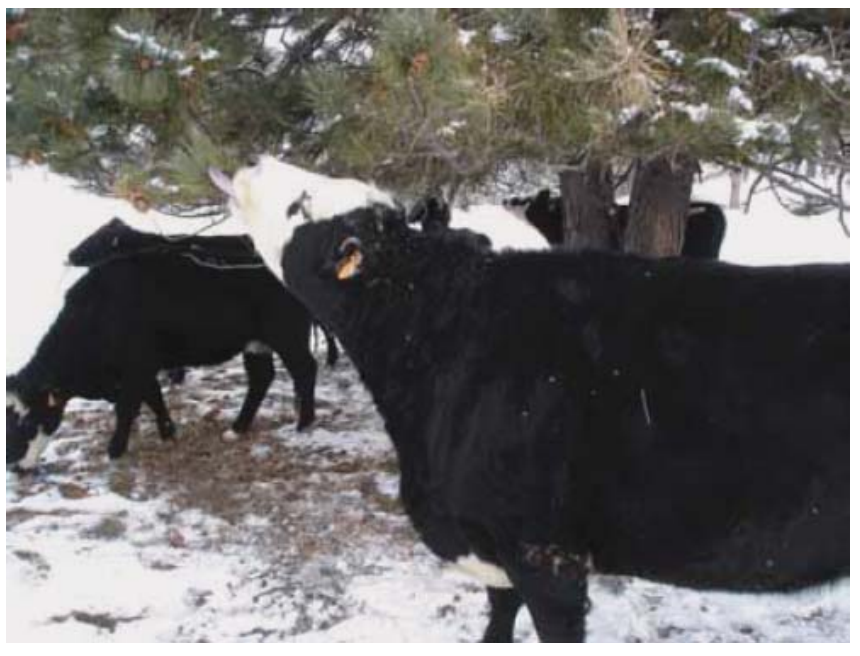

Figure 2. Cattle eating both fresh and dry pine needles in the Black Hills of South Dakota during winter, 2007. Photo courtesy of J. Pfister.

\begin{tabular}{|l|l|l|}
\hline \multicolumn{3}{|c|}{ Table 1. Pine needle collection sites } \\
\hline \multicolumn{1}{|c|}{ State } & County & City \\
\hline Arizona & Coconino & Flagstaff \\
\hline Montana & Custer & Miles City \\
\hline Oregon & Grant & Seneca \\
\hline South Dakota & Custer & Rapid City \\
\hline Utah & Dagget & Manila \\
\hline Wyoming & Albany & Laramie \\
\hline
\end{tabular}

Although there are no known methods to prevent pine needle-induced abortions, some basic recommendations can minimize the potential impact. First, deny pregnant cows access to pine needles during the later periods of pregnancy (third trimester) because this is when they are most susceptible. Second, provide adequate food and shelter to minimize pine needle consumption and losses due to pine needle abortion. Third, maintain pregnant cows in at least moderate to good body condition when grazing on pine needle-infested rangelands to reduce consumption and risk of abortions. Fourth, change the calving schedules to late spring or fall, thus minimizing the chance of experiencing weather conditions that drive cattle into the pine trees and lead to increased pine needle consumption. Lastly, if pine needle-induced abortion does occur, it is advisable to seek veterinary care for associated postpartum complications such as retained placenta and endometritis. Also, late-term calves might be alive at birth, but typically need extra care because they can be weak and might not suckle normally.

\section{ICA Concentrations in Pine Trees}

Currently, we do not know if the concentration of ICA in pine needles changes as a function of the environment or if there is location-to-location variation in ICA content. Because answers to these questions could influence management recommendations as they relate to pine needle abortion, the objective of our study was to monitor ICA content monthly for one year at six locations (Table 1). First, we ascertained if ICA content was uniform in individual trees in order to determine how to sample trees over time. We did so by making six individual collections from five different trees, as well as making a composite sample representing six individual points on each tree that were pooled as one sample. We sampled needles 2-3 inches from the growing tip from branches that could be reached without assistance. Table 2 shows the minimum, maximum, and average ICA concentration of the six individual collections from five trees, as well as the ICA concentration from a composite sample from each tree. ICA concentrations can vary up to two-fold on the same tree from individual collections, whereas the composite sample reflected more closely the mean of the six independent collections; therefore, we determined that it is best to make a composite sample to represent the ICA content of any individual tree. 
Table 2. Isocupressic acid (ICA) concentration (\% of dry weight) in needles collected from various points on the same tree at the same time

\begin{tabular}{|c|c|c|c|c|c|}
\hline & \multicolumn{5}{|c|}{ ICA Concentration (\%) } \\
\hline Tree & Min & Max & Average & SE & Composite \\
\hline 1 & 1.02 & 1.81 & 1.35 & 0.14 & 1.35 \\
\hline 2 & 0.65 & 0.88 & 0.75 & 0.04 & 0.58 \\
\hline 3 & 1.37 & 2.43 & 1.78 & 0.16 & 1.54 \\
\hline 4 & 0.76 & 1.34 & 1.05 & 0.11 & 0.77 \\
\hline 5 & 1.35 & 2.43 & 2.00 & 0.19 & 1.93 \\
\hline
\end{tabular}

Using this sampling method, we identified five trees at each location and sampled each tree monthly for a calendar year by making a composite sample representing multiple points on the tree. We collected samples on approximately the same day of each month and at the same time of day. Locations were chosen based upon previously documented cases of pine needle abortion (Table 1). Table 3 shows the minimum, maximum, and average ICA concentration throughout the calendar year $(5$ trees $\times 12$ months $=60$ independent measurements) at each location. Table 3 shows that some locations, such as Coconino County, Arizona, and Grant County, Oregon, had higher mean concentrations of ICA than places such as Albany County, Wyoming, and Dagget County, Utah. Figure 3, like Table 3, shows that some locations have greater ICA concentrations during some months in the calendar year than others. Figure 3 also shows that over the calendar year average, ICA concentrations remain fairly constant at some locations (such as Custer County, South Dakota, and Custer County, Montana), but at other locations (such as Coconino County, Arizona, and Grant County, Oregon) there are significant changes in average ICA concentrations during the year.

Table 3. Average isocupressic acid (ICA) concentration (\% of dry weight) in ponderosa pine trees from samples collected throughout the year at the various locations

\begin{tabular}{|l|l|l|l|l|}
\hline & \multicolumn{4}{|c|}{ ICA Concentration (\%) } \\
\hline \multicolumn{1}{|c|}{ Location } & Min & Max & Average & SE \\
\hline Coconino County, Arizona & 0.47 & 2.02 & $1.09^{\mathrm{a}}$ & 0.05 \\
\hline Custer County, Montana & 0.14 & 1.70 & $0.84^{\mathrm{ab}}$ & 0.06 \\
\hline Grant County, Oregon & 0.47 & 2.49 & $1.20^{\mathrm{a}}$ & 0.07 \\
\hline Custer County, South Dakota & 0.06 & 1.69 & $0.94^{\mathrm{ab}}$ & 0.07 \\
\hline Dagget County, Utah & 0.24 & 1.20 & $0.64^{\mathrm{b}}$ & 0.03 \\
\hline Albany County, Wyoming & 0.19 & 1.13 & $0.58^{\mathrm{b}}$ & 0.03 \\
\hline $\begin{array}{l}\text { ab Averages with different superscript letters indicate sig- } \\
\text { nificance at } P<0.14 .\end{array}$
\end{tabular}

a.

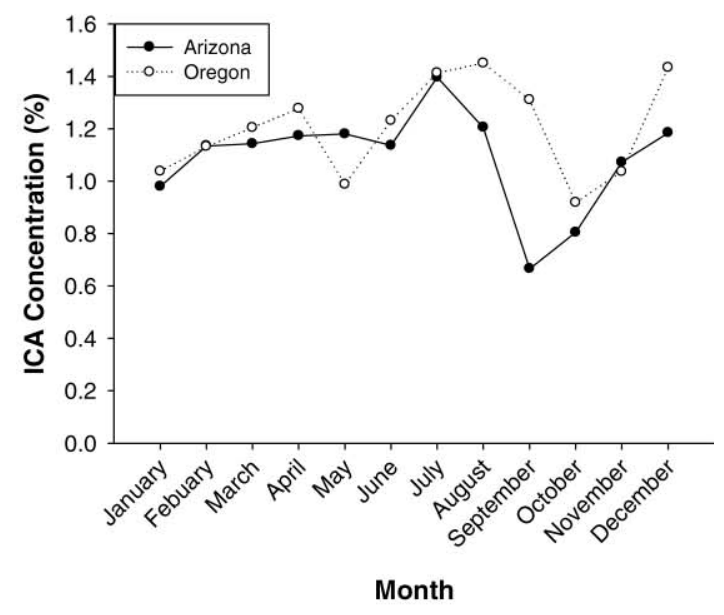

b.

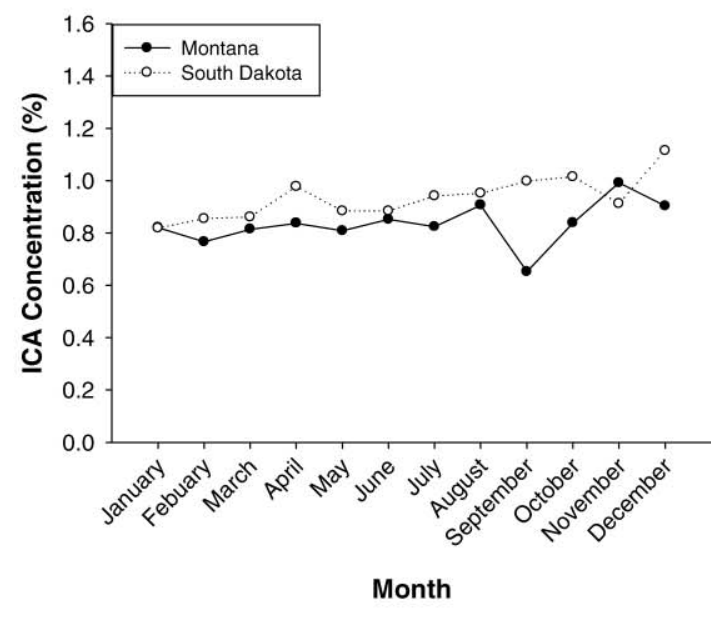

c.

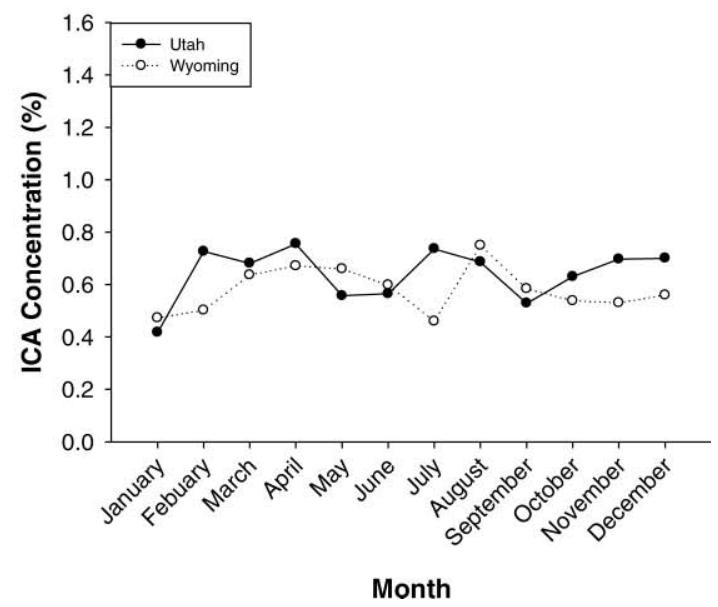

Figure 3. Mean isocupressic acid (ICA) concentrations in needles of the five ponderosa pine trees collected at each location: a, Arizona and Oregon; b, Montana and South Dakota; c, Utah and Wyoming. 
Our results indicate that the concentration of ICA in pine needles is not uniform throughout an individual tree. Consequently, collecting a composite sample from a tree is most representative of a tree's ICA content. In addition, ICA concentrations can vary between locations and between months at some locations, which might or might not be due to environmental conditions. This preliminary study provides the foundation for further detailed studies with a greater number of trees to determine 1) how the risk of abortions can vary between locations, 2) if ICA concentrations change as a function of the environment, and 3) if models can be developed to predict those changes and the subsequent risk of abortion.

\section{Acknowledgments}

The authors wish to thank Jessie Roper and Scott Larsen for their technical support. The authors also wish to thank the following individuals for their help in collecting the needles on a monthly basis at each of the locations: Tom Kolb, School of Forestry Northern Arizona University, Flagstaff, Arizona; Teresa Southworth, Seneca, Oregon; Rod Heitschmidt, USDA-Agricultural Research Service Fort Keogh LARRL, Miles City, Montana; Mr and Mrs Art Wierenga, Hermosa, South Dakota; and Brenda Johnson, Laramie, Wyoming.

\section{References}

1. Bruce, E. A. 1927. Astragalus serotinus and other stock poisoning plants of British Columbia. Dom Canada Department of Agriculture Bulletin 88:44.

2. MacDonald, M. A. 1952. Pine needle abortion in range beef cattle. Journal of Range Management 5:150-155.

3. James, L. F., J. W. Call, and A. H. Stevenson. 1977. Experimentally induced pine needle abortion in range cattle. Cornell Veterinarian 67:294-299.

4. James, L. F., R. E. Short, K. E. Panter, R. J. Moyneux, L. D. Stuart, and R. A. Bellow. 1989. Pine needle abortion in cattle: a review and report of 1973-1984 research. Cornell Veterinarian 79:39-52.

5. Short, R. E., L. F. James, K. E. Panter, R. B. Staigmiller, R. A. Bellows, J. Malcolm, and S. P. Ford. 1992. Effects of feeding pine needles during pregnancy: comparative studies with buffalo, goats, and sheep. Journal of Animal Science 70:3498-3504.

6. Bellows, S. E., R. E. Short, and S. P. Ford. 1996. Effects of feeding pine needles to late pregnant elk and goats. Proceedings of the Western Section of the American Society of Animal Science 47:186-188.

7. Conkle, M. T., and W. B. Critchfield. 1988. Genetic variation and hybridization of ponderosa pine. In: D. M. Baumgartner and J. E. Lotan [EDs.]. Ponderosa pine: the species and its management. Symposium Proceedings. Pullman, WA, USA: Cooperative Extension, Washington State University. p. 27-44.

8. Oliver, W. W., and R. A. Ryker. 1990. Pinus ponderosa Dougl. ex Laws. In: R. M. Burns and B. H. Honkala [eDs.].
Silvics of North America. Volume 1, Conifers. Agricultural Handbook 654. Washington, DC, USA: United States Department of Agriculture, Forest Service. p. 413-424.

9. James, L. F., R. J. Molyneux, K. E. Panter, D. R. Gardner, And B. L. Stegelmeier. 1994. Effect of feeding ponderosa pine needle extracts and their residues to pregnant cattle. Cornell Veterinarian 84:33-39.

10. Gardner, D. R., R. J. Molyneux, L. F. James, K. E. Panter, and B. L. Stegelmeier. 1994. Ponderosa pine needle induced abortion in beef cattle: identification of isocupressic acid as the principal active compound. Journal of Agriculture and Food Chemistry 42:756-761.

11. Gardner, D. R., K. E. Panter, R. J. Molyneux, L. F. James, and B. L. Stegelmeier. 1996. Abortifacient activity in beef cattle of acetyl- and succinyl-isocupressic acid from ponderosa pine. Journal of Agriculture and Food Chemistry 44:3257-3261.

12. Gardner, D. R., K. E. Panter, R. J. Molyneux, L. F. James, B. L. Stegelmeier, and J. A. Pfister. 1997. Isocupressic acid and related diterpene acids from Pinus ponderosa as abortifacient compounds in cattle. Journal of Natural Toxins 6:1-10.

13. Gardner, D. R., K. E. Panter, L. F. James, and B. L. Stegelmeier. 1998. The abortifacient effects of lodgepole pine (Pinus contorta) and common juniper (Juniperus communis) on cattle. Veterinary and Human Toxicology 40:260-263.

14. Gardner, D. R., And L. F. James. 1999. Pine needle abortion in cattle: analysis of isocupressic acid in North American gymnosperms. Phytochemical Analysis 10:132-136.

15. MacDonald, J. 1956. Macrocarpa poisoning. New Zealand Veterinarian 4:30.

16. Ford, S. P., L. K. Christenson, J. P. Rosazza, and R. L. Short. 1992. Effect of ponderosa pine needle ingestion on uterine vascular function in late-gestation beef cows. Journal of Animal Science 70:1609-1614.

17. Short, R. E., S. P. Ford, J. P. N. Rosazza, D. B. Farley, J. A. Klavons, and J. B. Hall. 1996. Effects of feeding pine needles and pine needle components to late pregnant cattle. Proceedings of the Western Section of American Society of Animal Science 47:193-196.

18. Pfister, J. A., And D. C. Adams. 1993. Factors influencing pine needle consumption by grazing cattle during winter. Journal of Range Management 46:386-390.

19. Pfister, J. A., K. E. Panter, and D. R. Gardner. 1998. Pine needle consumption by cattle during winter in western South Dakota. Journal of Range Management 51:551-556.

20. Pfister, J. A., K. E. Panter, D. R. Gardner, D. Cook, And K. D. WELCh. 2008. Effect of body condition on consumption of pine needles (Pinus ponderosa) by beef cattle. Journal of Animal Science 86:3608-3616.

Authors are Plant Physiologist, daniel.cook@ars.usda.gov (Cook), Chemists (Gardner and Lee), Rangeland Scientist (Pfister), Reproductive Toxicologist and Research Leader (Panter), Veterinary Pathologist (Stegelmeier), Toxicologist (Welch), Pharmacologist (Green), and Biochemist (Davis), Poisonous Plant Research Laboratory, Agricultural Research Service, United States Department of Agriculture, 1150 E $1400 \mathrm{~N}$, Logan, UT 84341, USA. 